\title{
THE STRATEGY HEAD MADRASAH STRENGTHENING THE QUALITY OF EDUCATION IN MADRASAH IBTIDAIYAH
}

\author{
Akmad Chostholani \\ Institut Pesantren KH Abdul Chalim Mojokerto \\ chostholani@gmail.com \\ Fadly Usman \\ Institut Pesantren KH Abdul Chalim Mojokerto \\ fadlypwk@ub.ac.id
}

\author{
Afif Zamroni \\ Institut Pesantren KH Abdul Chalim Mojokerto
}

Afifzam.ikhac@gmail.com

\begin{abstract}
This article aims to explain and analyze planning, implementation and evaluation strategies in strengthening the quality of education at Madrasah Ibtidaiyah Tarbiyatul Islamiyah Gresik. This article uses a qualitative research type with a descriptive design. This research takes place at Madrasah Ibtidaiyah Tarbiyatul Islamiyah Gresik. The research was carried out for three months, from February to May 2021. The technique of collecting data was observation, interviews with relevant informants and documentation. The results of this study are how madrasah strategies in strengthening the quality of education in institutions, both in terms of planning, implementation, and evaluation are strongly influenced by the madrasa head as a leader. Because all the strategies and policies used by the head of the madrasa determine the quality of an educational institution that is led. There are several things that the head of Madrasah Tarbiyatul Islmiyah does in strengthening the quality of education, including: 1) Providing examples of direct action with time discipline, 2) Carrying out programmatic and consistent implementation of activities, 3) Always evaluating programs carried out both internal and external evaluations. from outside so as to obtain accountable results.
\end{abstract}

Keyword: Education Strategy, Education Quality, Madrasah Ibtidaiyah.

\begin{abstract}
Abstrak
Artikel ini bertujuan untuk menjelaskan dan menganalisis strategi perencanaan, pelaksanaan dan evaluasi dalam menguatkan kualitas pendidikan di Madrasah Ibtidaiyah Tarbiyatul Islamiyah Gresik. Artikel ini menggunakan jenis penelitian kualitatif dengan desain deskriptif. Penelitian ini Bertempat di Madrasah Ibtidaiyah Tarbiyatul Islamiyah Gresik. Penelitian dilakukan selama tiga bulan yaitu dari bulan Februari hingga bulan Mei 2021. Tehnik pengambilan dengan dengan observasi, wawancara dengan informan yaang relevan serta dokumentasi. Hasil dari penelitian ini adalah bagaimana strategi madrasah dalam menguatkan kualiatas pendidikan dilembaga, baik dilihat dari perencanaan, pelaksanaan, maupun evaluasi sangat dipengaruhi oleh kepala madrasah sebagai leader. Karena segala strategi maupun kebijakan yang digunakan oleh kepala madrasah menentukan kualitas dari suatu lembaga pendidikan yang dipimpin. Ada beberapa hal yang dilakukan kepala Madrasah Tarbiyatul Islmiyah dalam menguatkan kualitas pendidikan antara lain: 1) Memberikan contoh tindakan secara langsung dengan disiplin waktu, 2) Melakukan pelaksanaan kegiatan yang terprogram dan konsisten, 3) Selalu melakukan evaluasi program yang dilaksanakan baik evaluasi dari dalam maupun dari luar sehingga memperoleh hasil yang akuntabel.
\end{abstract}

Kata Kunci: Strategi Pendidikan, Kualitas Pendidikan, Madrasah Ibtidaiyah 


\section{Pendahuluan}

Pendidikan adalah usaha yang dikerjakan secara jelas dan terencana untuk merealisasikan situasi belajar (Ilmi et al., 2021; Mufidah, 2021) dan kegaiatan pembelajaran sehingga siswa secara aktif dapat mengembangkan potensi diri untuk memiliki kemampuan spiritualitas keagamaan, kepribadian, kecerdasan, pengendalian diri, akhlak mulia dan termasuk keterampilan yang diperlukan dalam dirinya, masyarakat maupun bangsa (Khusnan, 2020; Rony \& Jariyah, 2020). Pendidikan adalah anggota tidak terpisahkan di dalam kehidupan setiap orang. Pendidikan berpengaruh pada pertumbuhan ekonomi suatu bangsa di dalam mengembangkan kualitas yang dimiliki manusia Indonesia(Muslimin \& Kartiko, 2020; Surya \& Rofiq, 2021). Pemerintah merupakan suatu proses yang tidak terlepas bersama dengan pihak swasta maupun masyarakat. Interaksi yang tak terpisahkan dalam kaitannya untuk tingkatkan kualitas pendidikan.

Pendidikan di harapkan untuk mampu dapat mencetak sumber kapabilitas manusia yang berkualitas (Mathis \& Jackson, 2011; Rosidi, 2018; Santosa \& Devi, 2021). Kenyataannya, pendidikan itu diharapkan mampu membuat persiapan tenaga yang terampil. Sementara itu, pada saat ini pendidikan nasional dihadapkan kepada kasus terhadap lain penguatan kualitas, pemerataaan pada kesempatan, keterbatasan pada anggaran dan belum terpenuhi sumber pada kapabilitas berasal berasal dari penduduk secara utuh sesuai dengan dengan komitmen pendidikan yang ada sebagai tanggung jawab bersama dengan pada masyarakat, pemerintah, dan orang tua (Abdullah, 2017; Ahmed, 2018).

Berbicara berkenaan mutu sumber kemampuan manusia, pendidikan memegang peran harus di dalam proses penguatan mutu sumber kemampuan manusia. Penguatan mutu pendidikan adalah suatu proses yang terpadu bersama proses peningkatan mutu sumber kemampuan manusia itu sendiri (Barirohmah \& Subiyantoro, 2021; Indana, 2018; Rahman, 2015). Menyadari betapa pentingnya proses penguatan mutu sumber daya manusia, maka pemerintah bersama kalangan swasta selamanya berusaha merealisasikan amanat melalui berbagai macam usaha pembangunan pendidikan yang lebih mempunyai mutu antara lain melalui perbaikan pembiayaan, pengembangan kurikulum dan juga proses evaluasi, perbaikan layanan pendidikan, pengembangan dan pengadaan materiaajar, dan juga pelatihan untuk guru dan tenaga kependidikan lainnya (Hasanah, 2015; Maarif \& Rofiq, 2018). 
ZAHRA: Research And Tought Elmentary School Of Islam Journal Vol. (2) (2), (Agustus)(2021), (Halaman)(153-166)| 155

Permasalahan mutu pendidikan memang selalu menjadi perhatian banyak pihak terutama lembaga pendidikan madrasah. Strategi kepala madrasah melakukan peningkatan kualitas dari berbagai macam cara diantaranya, melakukan: training bagi guru, workshop, seminar bahkan beasiswa bagi guru untuk melakukan pengembangan ke jengjang yang lebih tinggi (Danim, 2012; E Mulyasa, 2011; Hamzah B, 2007). Usaha tersebut belum tentu mampu untuk meningkatkan mutu lembaga. Terbukti di beberapa madrasah banyak yang kualitas masih dibawah rata-rata (Pratama, 2019; Subandi, 2020).

Dari beberapa permasalan diatas perlu penelitian yang lebih serius terkait pengembanan profesional guru serta upaya kepala sekolah dalam meningkatkan mutu pendidikan. Riset tahun 2016 oleh Abdul (Qohar, 2016) menghasilkan bahwa peningkatan mutu perlu melibatkan masyarakat. Selanjutnya tahun 2017 riset dilakukan oleh (MOCH ARIF BURHANUDIN, 2018) meningkatkan mutu mulai dari hal terkecil hingga perlu melakukan analisis SWOT. Riset tahun 2018 Yuli Dwi (Indahwati, 2018) menghasilkan bahwa kepala sekolah perlu memberikan kompetensi tambahan bagi guru terutama melek terhadap teknologi. Dari beberapa riset tersebut penulis melihat bahwa masih belum banyak diteliti terkait stategi kepala madrasah meningkatkan mutu di lembaga Madrasah Ibtidaiyah dengan model perencanaan, pelaksanaan dan evaluasi.

Penulis tertarik meneliti terkait upaya lembaga beserta kepala sekolah meningkatkan mutu penddikan di Madrasah Ibtidaiyah Tarbiyatul Islamiyah Gresik dikarenakan selama melakukan observasi, penulis menemukan progres yang dilakukan oleh kepala madrasah. Selama beberapa tahun ini selalu melakukan inovasi-inovasi yang tidak dilakukan oleh lembaga lain. Penulis ingin mendeskripsikan dan menganalisis perencanaan, pelaksanaan dan evaluasi strategi kepala madrasah dalam meningkatkan mutu pendidikan di Madrasah Ibtidaiyah (MI).

\section{Metode Penelitian}

Artikel ini menggunakan jenis penelitian kualitatif dengan pendekatan studi kasus. Alasan menggunakan studi kasus adalah di tempat yang diteliti memiliki permasalah terkait bagiamana strategi kepala sekolah dalam merencanakan, melaksanakan dan mengevaluasi mutu dan kualitas pendidikan madrasah. Penelitian ini bertemapat di Madrasah Ibtidaiyah (MI) Tarbiyatul Islamiyah Desa Tanjungan Kecamatan Driyorejo Kabupaten Gresik. Pelaksanaan penelitian ini dilakukan selama bulan Februari hingga Mei 2021. Informan penelitian ini adalah, kepala Madrasah, wakil kapala madrasah dan beberapa Guru yang bersangkutan. Tehnik pengumpulan data dengan observasi, wawancara dan dokumentasi. Wawancara yang dilakukan dengan informan dilakukan dengan formal dan non formal. Teknik pengumpulan data merupakan suatu upaya mengamati variabel dengan teliti melalui metode observasi, wawancara dan dokumentasi. Tehnik analisis dat mengikuti model 
ZAHRA: Research And Tought Elmentary School Of Islam Journal Vol. (2) (2), (Agustus)(2021), (Halaman)(153-166)| 156 (Creswell, 2007; Miles et al., 2014) yaitu dengan 1) reduksi data, 2) penyajian data dan, 3) verivikasi dan penarikan kesimpulan.

\section{Hasil Penelitian dan Diskusi Data}

\section{Perencanaan Kepala Madrasah Dalam Meningkatkan Kualitas Lembaga}

Proses penyusunan rencana pada madrasah Ibtida'iyah tarbiyatul Islamiyah dilakukan pada awal tahun ajaran yakni pada saat penyusunan Kurikulum Madrasah, Adapun strategi yang dilakukan dibagi ddalam eempat tahap, yaitu (1) diagnosis, (2) perencanaan, (3) pengembangan dan (4) penyusunan dokumen rencana.

Pertama, Tahap diagnosis, dimulai dengann pengumpulan berbagaii informasi perencanaan sebagaii bahan kajian.. Kajian lingkungan internal bertujuann untuk memahami kekuatan-kekuatan dann kelemahan kelemahan dalam pengelolaan pendidikan di MI Tarbiyatul Islamiyah.. Sementara kajian lingkungan eksternal bertujuan untuk mengungkap peluang-peluang dann tantangan-tantangan dalam penyelenggaran pendidikan.. Secara visual tahapan dalam proses penyusunan perencanaan strategis

Kedua, Tahap perencanaan, dimulai dengann menetapkan visi dan misi. Visi merupakan gambaran (wawasan) tentang keadaan yang diinginkan di masa depan. Sementara misi (mission) ditetapkan dengan jalan mempertimbangkan rumusan penugasan, yang merupakan tuntutan tugas dari luar organisasi dan keinginan dari dalam berkaitan dengan visi masa depan dan situasi yang dihadapi saat ini.

Ketiga, Tahap pengembangan, dirumuskan berdasarkan misi yang diemban dan dalam rangka menghadapi isu utama (isu strategis). Urutan strategi pengembangan disusun sesuai dengan isu-isu utama. Dalam rumusan strategi, pengembangan dapat dibedakan menurut kelompok strategi, dengan rincian terdiri atas tiga tingkat (seperti strategi utama, substrategi, dan rincian strategi). Hubungan antara visi, misi dan tujuan pada MI Tarbiyatul Islamiyah.

Keempat, Tahap penyusunan dokumen rencana strategis, dirumuskan secara singkat, tidak terlampau tebal sehingga ringan dimengerti dan sanggup ditunaikan oleh tim manajemen secara luwes. Perumusannya sanggup ditunaikan sejak kala pengkajian sudah menghasilkan temuan. Untuk penyelesaian akhir harus menunggu hingga seluruh keputusan atau rumusan sudah ditetapkan atau disepakati oleh seluruh pihak yang terkait. Rumusan visi yang disepakati bersama dapat dijadikan sebagai arahan dalam merumuskan misi dan obyek organisasi pendidikan. Hasil kajian berkenaan kemampuan dan kelemahan organisasi pendidikan dan juga kesempatan dan tantangan eksternalnya di suatu sisi dan juga rumusan visi, misi, dan obyek organisasi pendidikan sanggup menghasilkan isu-isu utama dalam pembangunan pendidikan dalam konteks masing-masing. Alternatif rencana yang paling baik adalah alternatif rencana yang paling memungkinkan untuk dilaksanakan, yang paling banyak kontribusinya bagi pergerakan pertumbuhan dalam aspek-aspek berkaitan dan yang memungkinkan ada pergantian manakala dalam sistem implementasinya butuh ada penyesuaian kondisi. 
ZAHRA: Research And Tought Elmentary School Of Islam Journal Vol. (2) (2), (Agustus)(2021), (Halaman)(153-166)| 157

Hal tersebut senada dengan apa yang dikemukakan oleh (Mulyasa, 2013) bahwa Perencanaan memuat: (1) diagnosis, (2) perencanaan, (3) pengembangan dan (4) penyusunan dokumenn rencana. Setiap tahap dilakukan dengan cermat dan datail agar dalam melaksanakan atau mengimplementasikan program lembaga tidak banyak kendala yang dihadapi. Perencanaan tentunya tidak hanya dilakukan sendiri oleh kepala akan tetapi melibatkan beberpa stake holder (Chalim et al., 2020; Winarti, 2018).

Hal tersebut diatas selamanya dilakukan oleh Madrasah yang dipimpin oleh Bapak H Idham Kholid, S.Pd selaku kepala Madrasah. berkoordinasi dengan yayasan selaku perencanaan awal sebelum dilakukan perencanaan ditingkat kepala madrasah. Perencanaan yang dilakukan dengan pengurus yayasan mengenai kebutuhan sarana dan prasarana yang dibutuhkan oleh lembaga, Dari pengajuan kepala Madrasah yakni Bapak H.Idham Kholid, S.PdI yang selanjutnya membuat suatu perencanaan anggaran terkait dengan strategi pengadaan, pembiayaan maupun realisasi.

Manfaat perencanaan pendidikan. Menurut para ahli, ada beberapa manfaat dari suatu perencanaan pendidikan yang disusun dengan baik bagi kehidupan kelembagaan, antara lain: (1) dapat digunakan sebagai standar pelaksanaan dan pengawasan proses aktivitas atau pekerjaan pemimpin dan anggota dalam suatu lembaga pendidikan; (2) dapat dijadikan sebagai media pemilihan berbagai alternatif langkah pekerjaan atau strategi penyelesaian yang terbaik bagi upaya pencapaian tujuan pendidikan; (3) dapat bermanfaat dalam penyusunan skala prioritas kelembagaan baik yang menyangkut sasaran yang akan dicapai maupun proses kegiatan layanan pendidikan; (4) dapat mengefisiensikan dan mengefektifkan pemanfaatan beragam sumber daya organisasi atau lembaga pendidikan; (5) dapat membantu pimpinan dan para anggota (warga sekolah) dalam menyesuaikan diri terhadap perkembangan atau dinamika perubahan sosial-budaya; (6) dapat dijadikan sebagai media atau alat untuk memudahkan dalam berkoordinasi dengan berbagai pihak atau lembaga pendidikan yang terkait, dalam rangka meningkatkan kualitas layanan pendidikan; (7) dapat dijadikan sebagai media untuk meminimalkan pekerjaan yang tidak efisien atau tidak pasti; dan (8) dapat dijadikan sebagai alat dalam mengevaluasi pencapaian tujuan proses layanan pendidikan (Belcourt \& McBey, 2013; Hamalik, 2003; Ikhwan, 2016).

Disini selaku ketua Yayasan H Isa selalu berkoordinasi dengan kepala madrasah apa saja kebutuhan madrasah yang belum terpenuhi, dan dijadikan acuan perencanaan anggaran kepala madrasah selama 1 tahun kedepan baik sarana prasarana maupun kegiatan belajar mengajar. Adapun Strategi Kepala Madrasah salah satunya adalah peningkatan mutu madrasah, Sebagaimana diungkapkan dalam pasal 12 ayat 1 PP 28 tahun 1990 bahwa: "Kepala Madrasah bertanggung jawab atas penyelenggaraan kesibukan pendidikan, administrasi sekolah, pembinaan tenaga kependidikan lainya, dan pendayagunaan serta pemeliharaan sarana dan prasarana (Mulyasa, 2006).” Kepala Madrasah dalam menguatkan kompetensi profesional guru harus mempunyai strategi agar tugas kepemimpinannya berjalan dengan lancar. Bapak Idham Kholid, S.Pd.I Kepala Madrasah berusaha 
ZAHRA: Research And Tought Elmentary School Of Islam Journal Vol. (2) (2), (Agustus)(2021), (Halaman)(153-166)| 158 mengupayakan bagaimana agar guru yang ada di MI Tarbiyatul Islamiyah bisa menguatkan kompetensi profesional, strategi yang dilakukan antara lain :

\section{Strategi Formal}

\section{a. Diikutkan kursus dan pelatihan guru.}

Mengikutkan guru di dalam Kegiatan Pendidikan dan Pelatihan Tenaga Guru (PPTG) dan tenaga kependidikan terhadap umumnya. Hal ini ditujukan supaya guru bisa merespon pergantian dan tuntutan pertumbuhan IPTEK dan kemajuan kemasyarakatan, terhitung pergantian proses pendidikan dan pembelajaran secara mikro (Danim, 2012).

Di MI Tarbiyatul Islamiyah sering mengikutkan Bapak Ibu guru dalam pelatihan, seminar, diklat dalam rangka meningkatkan prestasi dan wawasan mengenai pendidikan. Pelaksanaan penataran dan lokakarya untuk mengembangkan kekuatan guru dalam laksanakan sistem studi mengajar. Pelaksanaannya di dilaksanakan bersama dengan cara mengundang seorang atau lebih dari satu orang pakar sebagai narasumber.

Terlebih terhadap selagi masa pandemi bapak/Ibu Guru dituntut untuk laksanakan pembelajaran secara daring yang mampu memotivasi peserta didik bersama dengan baik. Diklat mampu dilangsungkan dari bilangan jam sampai bilangan bulan cocok bersama dengan kebutuhan dan keinginan. Diklat mampu diadakan bersama dengan materi cocok bersama dengan kebutuhan atau permohonan agar nyaris semua manfaat pendidikan di sekolah mampu di diklatkan: manajemen, kepemimpinan, sistem studi mengajar, administrasi, dll (Fitriani et al., 2017; Rosyada, 2017).

Karena keluwesan diklat nyaris terhadap semua aspeknya, diklat sering dijadikan jalan muncul untuk mengatasi kasus kualitas guru di MI. Tarbiyatul Islamiyah. Catatan yang harus diungkap agar diklat mampu terlampau menjadi solusi bagi kasus kualitas guru adalah bahwa pelaksanaan diklat hendaknya setia kepada tujuan.

\section{b. Diikutkan Seminar}

Seminar adalah suatu rangkaian kajian yang diikuti oleh suatu kelompok untuk mendiskusikan, membahas dan memperdebatkan suatu kasus yang berhubungan bersama topik. Berkaitan bersama pelaksanaan supervisi, dalam seminar ini sanggup dibahas layaknya bagaimana menyusun silabus sesuai standar isi, bagaimana menanggulangi kasus disiplin sebagai segi ethical Madrasah, bagaimana menanggulangi anak-anak yang tetap sebabkan keributan dikelas, dll (Bustamar et al., 2016; Darmadi, 2016).

Sebuah seminar biasanya miliki fokus terhadap suatu topik yang khusus, di mana mereka yang hadir sanggup berpartisipasi secara aktif. Seminar sering ditunaikan lewat sebuah dialog bersama seorang maderator seminar, atau lewat sebuah presentasi hasil penelitian dalam wujud yang lebih formal. Sistem seminar miliki gagasan untuk lebih mendekatkan mahasiswa kepada topik yang dibicarakan. Seminar merupakan suatu pembahasan kasus secara ilmiah, meskipun topik yang dibahas adalah kasus sehari-hari. Dalam membahas masalah, tujuannya adalah 
ZAHRA: Research And Tought Elmentary School Of Islam Journal Vol. (2) (2), (Agustus)(2021), (Halaman)(153-166)| 159 melacak suatu pemecahan kasus (Sulistyorini, 2012). Oleh karena itu, suatu seminar senantiasa diakhiri bersama pemikiran atau keputusan-keputusan yang merupakan hasil pendapat bersama. Pembahasan seminar berpangkal makalah atau kertas kerja yang sudah disusun pada mulanya oleh beberapa pembicara cocok bersama pokok bahasan yang diminta oleh suatu penyelenggara yang dapat dibahas secara teoritis(Ariyanto \& Sulistyorini, 2020; Liu, 2020).

Pembahasan didalam seminar memakan sementara yang lebih lama karena sifatnya yang ilmiah. Apabila para pembicara tidak bisa yang tidak cukup penting. Oleh karena itu, dibutuhkan pimpinan kelompok yang menguasai persoalan, sehingga penyimpangan dari pokok masalah bisa dicegah (Siagian, 2003). Dalam menaikkan kompetensi profesional guru, Kepala Madrasah mendorong guru untuk kreatif dan inovatif dengan lakukan sebagian pendekatan pada guru-guru dan staf terutama guru yang berada di MI Tarbiyatul Islamiyah.

\section{c. Mengikutkan Program KKG (Kelompok Kerja Guru)}

Pada MI Tarbiyatul Islamiyah guru diharuskan ikuti KKG baik Guru Kelas maupun Mata Pelajaran, yang merupakan suatu organisasi guru yang dibentuk untuk jadi forum komunikasi yang bertujuan untuk memecahkan kasus yang dihadapi guru di dalam pelaksanaan tugasnya sehari-hari di lapangan (Arif et al., 2020). Guru amat berterima kasih kepada bapak Kepala Madrasah sebab ada kesibukan KKG.

\section{Pelaksanakaan Kegiatan dalam Meningkatkan Kualitas Lembaga}

Dalam pelaksanaan menguatkan kualitas pendidikan di MI Tarbiyatul Islamiyah, ada beberapa hal yang dilakukan oleh Madrasah. MI Tarbiyatul Islamiyah selalu utamakan kedisiplinan baik itu untuk siswa maupun gurunya. Kedisiplinan itu di mulai oleh Bapak H Idham Kholid, selaku Kepala Madrasah. Dari hasil pengamatan peneliti kebanyakan berangkat jam 6. 40 lebih pagi dari guru-guru yang lain, berangkat lebih awal dan pulang lebih akhir. Jam masuk sekolah terhadap jam 06.30 dan selesai pembelajaran terhadap jam13.20 WIB, akan namun bapak H Idham Kholid, menyita kebijakan bahwa guru tidak perlu berangkat jam 06. 40 akan namun setidaknya datang kira-kira 10 menit sebelum jam pelajaran di jadi tata teratur ini lebih dikhususkan terhadap guru yang mengajar terhadap jam pelajaran pertama.

Sebelum Kegiatan jam pertama ada pembiasaan yang diselenggarakan di MI Tarbiyatul Islamiyah yakni sholat dhuha berjamaah yang dikomando segera oleh Bapak H.Idham Kholid,guruguru menjadi rajin dan segan jika datangnya terlambat. Kalau ada guru yang tidak masuk mengajar guru berikut wajib memberi surat izin beserta alasan yang pas tidak masuk mengajar dan wajib memberi tugas kepada peserta didik. Jadi meskipun guru tidak ada siswa senantiasa dapat laksanakan proses pembelajaran sebagaimana mestinya. Kedisiplinan tidak cuma bertujuan terhadap peserta didik dapat tetapi guru juga wajib ditingkatkan kedisiplinannya karena guru sebagai contoh bagi peserta didiknya.

Sebagai pemimpin yang bertanggung jawab pada pencapaian Tujuan bersama dengan melalui orang lain atau karyawan, mereka diinginkan membawa kapabilitas untuk memotivasi para 
ZAHRA: Research And Tought Elmentary School Of Islam Journal Vol. (2) (2), (Agustus)(2021), (Halaman)(153-166)| 160 karyawan.dengan memahami apa yang menjadi keperluan mereka dan mengusahakan untuk menyiapkan alat-alat pemenuhan keperluan para karyawan maka seorang pemimpin akan mampu mendorong para karyawannya untuk bekerja lebih giat (Arifin, 2017; Fauzi, 2017; Kartiko et al., 2020).Sebagai motivator Bapak H.Idham Kholid, memiliki trik yang tepat untuk beri tambahan motivasi kepada tenaga pendidik di dalam melaksanakan beragam tugas dan fungsinya. Motivasi itu mampu ditumbuhkan melalui :

\section{a. Penyediaan Sarana dan Prasarana yang Memadai}

Sarana yang membantu dan cukup merupakan harapan berasal dari seluruh sekolah, juga harapan berasal dari Kepala Madrasah mengupayakan untuk memperbaiki fasilitas yang ada, supaya guru merasa nyaman di dalam mengajar. Prasarana atau perlengkapan juga merupakan penunjang di dalam sistem belajar mengajar. MI Tarbiyatul Islamiyah salah satu fasilitas prasarana yang disediakan oleh Kepala Madrasah yang bekerjasama dalam pengadaan sesuai dengan perencanaan adalah penyediaan LCD di kelas-kelas, biarpun belum terealisasi seluruhnya, waktu ini masih terhadap sistem pemenuhan LCD ke semua kelas.

Selain itu termasuk terkandung CCTV di kelas-kelas untuk mengawasi jalannya sistem belajar mengajar berasal dari kantor Kepala Madrasah. Selain itu dalam menagulangi kesulitan yang ada pada masa pademi dalam proses kegitan belajar mengajar, selain memotifasi guru untuk melakukan pembelajaran daring yang mengedepankan pelayanan pembajaran yang lebih maksimal, madrasah juga memiliki WEB untuk melakukan kemudahan dan pelayanan yang lebih baik pada peserta didik. Profesionalisme tenaga pendidikan mesti ditingkatkan, untuk itu Bapak $\mathrm{H}$ Idham Kholid, berusaha menanamkan disiplin kepada semua bawahannya. Melalui disiplin ini diharapkan dapat tercapai obyek secara efektif dan efisien, serta dapat menghasilkan lulusan yang berkualitas (Arif et al., 2021).

\section{b. Dorongan}

Setiap tenaga kependidikan punyai karakteristik yang tidak serupa satu bersama dengan yang lainnya, supaya memerlukan perhatian dan layanan tertentu pula berasal dari pemimpinnya, supaya mereka mampu manfaatkan sementara untuk menguatkan profesionalismenya. Bapak H Idham Kholid, memotivasi seluruh tenaga pendidik dan staf guru lain untuk konsisten berkreasi didalam meningkatkan kualitas pembelajaran.

Menguatkan kompetensi profesional guru memerlukan motivasi dan dukungan berasal dari beraneka pihak, seperti halnya motivasi berasal dari Kepala Madrasah. Bapak H.Idham Kholid, sebagai Kepala Madrasah selamanya mendorong atau memberi tambahan motivasi kepada seluruh guru, untuk lebih kreatif dan inovatif didalam proses pembelajaran di kelas bersama dengan motivasi berasal dari Kepala Madrasah seperti itu, maka guru jadi motivasi didalam menggerakkan tugasnya. Dorongan seluruh guru juga memotivasi dirinya sendiri untuk meningkatkan kompetensi profesionalnya. Penggunaan IT dalam kegitan pembelajaran 
ZAHRA: Research And Tought Elmentary School Of Islam Journal Vol. (2) (2), (Agustus)(2021), (Halaman)(153-166)| 161 merupakan kebutuhan dasar yang harus di miliki untuk melakukan pembelajaran pada masa pandemic seperti sekarang ini yakni pembelajaran jarak jauh (daring).

\section{Evaluasi Kepala Madadrasah dalam Meningkatkan Kualitas Lembaga}

Dalam melakukan evaluasi bapak H.Idham Kholid selaku kepala Madrasah melakukan kegiatan evaluasi secara rutin tiap akhir tahun pembelajaran dalam upaya menguatkan kualiatas pendidikan di MI Tarbiyatul Islamiyah yakni Evaluasi dari dalam dan evaluasi dari luar.

\section{a. Evaluasi internal}

Yang dimaksud bersama dengan evaluaasi berasal dari di dalam adalah petugas evaluasi program yang sekaligus merupakan tidak benar saeorang berasal dari anggota pelaksana program yang evaluasi. Berdasarkan batasan selanjutnya maka di dalam evaluasi program pembelajaran guru jadi evaluator berasal dari di dalam gara-gara guru tidak cuman sebagai perencana sekaligus pelaksana program pembelajaran membawa kewajiban menilai, sikap dan tabiat maupun partisipasi siswa di dalam proses pembelajaran, terhitung membawa kewajiban menilaihasil belajar siswa. Adapun berlebihan dan kekurangan evaluator berasal dari di dalam antara lain : 1) Evaluator tahu betul program yang akan dievaluasi agar ke-khawatiran untuk tidak atau kurang tepatnya sasaran tidak harus ada. Dengan kata lain, evaluasi pas terhadap sasaran. 2) Karena evaluator adalah orang dalam, pengambil ketentuan tidak banyak mengeluarkan pas dan cost yang memadai banyak (Bahrissalim \& Fauzan, 2018; Shodiq et al., 2017).

Kekurangan Evaluator dari dalam. 1) Adanya unsur subjektivitas berasal dari evaluator, sehingga berusaha menyampaikan faktor positif berasal dari program yang dievaluasi dan menghendaki sehingga kebijakan tersebut dapat diimplementasikan bersama dengan baik pula. Dengan kata lain, evaluator internal dapat dikhawatirkan bakal melakukan tindakan subjektif. 2) Karena sudah mengerti seluk belum program, kecuali evaluator kurang sabar, kesibukan evaluasi bakal ditunaikan bersama dengan tergesa-gesa sehingga kurang cermat.

\section{b. Evaluasi External}

Evaluator berasal dari luar adalah orang-orang yang tidak perihal bersama dengan implementasi program (Arif \& Sulistianah, 2019). Pengambil ketetapan untuk mengevaluasi keberhasilan program pembelajaran. Termasuk evaluator eksternal didalam evaluasi program pembelajaran di antaranya evaluasi yang ditunaikan petugas yang ditunjuk oleh kepala sekolah maupun evaluasi yang ditunaikan oleh petugas yang ditunjuk oleh dinas pendidikan.

Kelebihan Evaluator berasal dari luar: Karena tidak berkepentingan atas keberhasilan program pembelajaran, evaluator berasal dari luar mampu bertindak secara efisien sepanjang laksanakan evaluasi dan menyita kesimpulan. Apapun hasil evaluasi tidak bakal ada tanggapan emosional berasal dari evaluator dikarenakan tidak ada keinginan untuk perlihatkan bahwa program selanjutnya berhasil. Kesimpulan yang dibuat bakal lebih cocok bersama dengan situasi dan kenyataan yang sebenarnya. Seorang ahli yang ditunjuk biasanya bakal mempertahankan 
ZAHRA: Research And Tought Elmentary School Of Islam Journal Vol. (2) (2), (Agustus)(2021), (Halaman)(153-166)| 162 kredibilitas kemampuannya, bersama dengan begitu ia bakal bekerja secara betul-betul dan hatihati.

Kekurangana Evaluator berasal dari luar: Evaluator berasal dari luar biasanya belum mengenal lebih didalam perihal program pembelajaran yang bakal dievaluasi. Hal itu wajar dikarenakan evaluator tidak turut didalam proses kegiatannya. Mereka mengusahakan mengenal dan mempelajari seluk beluk program selanjutnya setelah mendapat keinginan untuk mengevaluasi. Dampak berasal dari kekurang pengetahuan selanjutnya amat mungkin asumsi yang diambil kurang tepat (Mahfud, 2019).

Pemborosan waktu dan biaya, pengambil ketetapan wajib mengeluarkan saat dan ongkos untuk membayar evaluator tersebut. Melihat kelebihan dan kekurangan berasal dari masingmasing aktivitas evaluasi, dan juga untuk lebih mengoptimalkan peran guru didalam evaluasi program pembelajaran, maka Bapak H.Idham Kholid, S.Pd.I sebagai evaluasi program pembelajaran mengkombinasi pada evaluator berasal dari didalam dan evaluator berasal dari luar. Yakni bersama dengan laksanakan evaluasi program pembelajaran terhadap tiap-tiap akhir pelaksanaan pembelajaran perihal bersama dengan satu kompetensi dasar atau satu pokok bahasan evaluasi ditunaikan oleh guru yang merancang dan laksanakan aktivitas pembelajaran.

Sedangkan untuk evaluasi program pembelajaran yang berasal dari luar, terhadap tiap-tiap akhir semester atau terhadap akhir tahun selamanya membuat kuisoner yang diberikan kepada tiap-tiap wali santri untuk beri tambahan tanggapan perihal aktivitas pembelajaran sepanjang satu tahun, hasil berasal dari kuisoner direkap oleh Ibu Sugiastutik sebagai guru konseling dan kurikulum.

Sebagai tindak lanjut evaluasi baik evaluasi berasal dari didalam maupun berasal dari luar bakal dibahas terhadap saat aktivitas rapat akhir tahun yang ditunaikan setelah laksanakan Penialiaan Akhir Tahun (PAT) dilanjut bersama dengan rapat Kenaikan kelas. Hal ini ditunaikan sebagai bahan evaluasi sepanjang aktivitas satu tahun dan sebagai pijakan aktivitas yang bakal ditunaikan sepanjang satu tahun kedepan.

\section{Simpulan}

Bahwa perencanaan yang dilakukan dengan baik bersama pemangku kebijakan akan dapat menghasilkan sebuah pemikiran ataupun gagasan dan dilaksanakan sesuai prosedur akan dapat menghasilkan suatu hasil yang baik sesuai dengan harapan. Langkah-langkah Madrasah di dalam menguatkan kualitas pendidikan di MI Tarbiyatul Islamiyah terbagi ke dalam dua kegiatan strategi, yang pertama langkah resmi yakni guru ditugaskan oleh lembaga mengikuti pendidikan \& pelatihan, baik yang dilakukan lembaga sekolah itu sendiri maupun oleh lembaga pendidikan/pelatihan, karena tuntutan pekerjaan untuk sementara ini atau jaman datang seperti : diikutkan pelatihan guru, seminar dan program KKG, dan langkah non resmi yakni guru atas permintaan dan usaha sendiri melatih dan mengembangkan dirinya yang berhubungan bersama pekerjaan atau jabatannya seperti : Kedisiplinan, diskusi, kolaborasi dan berikan motivasi. Ada lebih dari satu rintangan yang dihadapi didalam 
ZAHRA: Research And Tought Elmentary School Of Islam Journal Vol. (2) (2), (Agustus)(2021), (Halaman)(153-166)| 163 mengembangkan kompetensi profesional guru untuk menguatkan kualitas pendidikan di MI Tarbiyatul Islamiyah kendala-kendalanya pada lain : kurang atau keterbatasan penguasaan IT di Madrasah dan keterbatasan waktu, kurang kreatifitas guru di dalam proses pembelajaran di kelas dan kurang banyaknya koleksi buku atau layanan sekolah, terlebih di masa penemi seperi sementara ini yang menuntut kreatifitas guru perihal pembelajaran secara online, serta kurang ada hasil karya ilmiah yang dibikin oleh guru-guru. Evaluasi yang dilakukan secara terbuka dan akuntabel dapat memberikan hasil yang maksimal untuk dapat menguatkan kualitas pendidikan pada suatu lembaga Pendidikan.

\section{Daftar Pustaka}

Abdullah, M. A. (2017). Islamic Studies in Higher Education in Indonesia: Challenges, Impact and Prospects for the World Community. Al-Jami'ah: Journal of Islamic Studies, 55(2), 391-426. https://doi.org/10.14421/ajis.2017.552.391-426

Ahmed, F. (2018). An exploration of Naquib al-Attas' theory of Islamic education as ta'dīb as an 'indigenous' educational philosophy. Educational Philosophy and Theory, 50(8), 786-794. https://doi.org/10.1080/00131857.2016.1247685

Arif, M., Bahrozi, I., \& Hudah, N. (2020). Madrasah Ibtidaiyah Transformation Based on Pesantren in the Era of Industrial Revolution 4.0. PSYCHOLOGY AND EDUCATION, 16.

Arif, M., Rahmayanti, J. D., \& Rahmawati, F. D. (2021). Penanaman Karakter Peduli Sosial Pada Siswa Sekolah Dasar. Qalamuna:Jurnal Pendidikan, Sosial, dan Agama, 13(2), 289-308. https://doi.org/10.37680/qalamuna.v13i2.802

Arif, M., \& Sulistianah, S. (2019). Problems in 2013 Curriculum Implementation for Classroom Teachers in Madrasah Ibtidaiyah. Al Ibtida: Jurnal Pendidikan Guru MI, 6(1), 110. https://doi.org/10.24235/al.ibtida.snj.v6i1.3916

Arifin, Z. (2017). The Authority of Spiritual Leadership at Pesantren Temboro Based on Jamaah Tabligh Ideology. Jurnal Pendidikan Islam, 6(2), 265-292. https://doi.org/10.14421/jpi.2017.62.265-292

Ariyanto, A., \& Sulistyorini, S. (2020). Konsep motivasi dasar dan aplikasi dalam lembaga pendidikan Islam. AL-ASASIYYA: Journal Of Basic Education, 4(2), 103-114. https://doi.org/10.24269/ajbe.v4i2.2333

Bahrissalim, B., \& Fauzan, F. (2018). Evaluasi Kurikulum Pelatihan Dalam Meningkatkan Kompetensi Pedagogik Guru Pai Di Balai Diklat Keagamaan Jakarta. Edukasia: Jurnal Penelitian Pendidikan Islam, 13(1), 25-52. https://doi.org/10.21043/edukasia.v13i1.2779

Barirohmah, B., \& Subiyantoro, S. (2021). ISO 9001:2008 Quality Management System In Education. Nazhruna: Jurnal Pendidikan Islam, 4(2), 353-361. https://doi.org/10.31538/nzh.v4i2.1485

Belcourt, M., \& McBey, K. J. (2013). Strategic human resources planning (5th ed.). Nelson Education.

Bustamar, Idris, J., \& Khairuddin. (2016). Strategi Kepala Sekolah Dalam Pengembangan Profesional Tenaga Kependidikan Pada Sma Negeri 5 Darussalam Banda Aceh. Jurnal Administrasi Pendidikan: Program Pascasarjana Unsyiah, 4(1). http://www.jurnal.unsyiah.ac.id/JAP/article/view/2603

Chalim, S., Sujono, G., \& Usman, F. (2020). Trend Analysis Based Educator Planning. Nazhruna: Jurnal Pendidikan Islam, 3(2), 273-284. https://doi.org/10.31538/nzh.v3i2.683

Creswell, J. W. (2007). Qualitative inquiry \& research design: Choosing among five approaches (2nd ed). Sage Publications. 
ZAHRA: Research And Tought Elmentary School Of Islam Journal Vol. (2) (2), (Agustus)(2021), (Halaman)(153-166)| 164

Danim, P. D. S. (2012). Pengembangan Profesi Guru. Prenada Media.

Darmadi, H. (2016). Tugas, Peran, Kompetensi, Dan Tanggung Jawab Menjadi Guru Profesional. Edukasi: Jurnal Pendidikan, 13(2), 161-174. https://doi.org/10.31571/edukasi.v13i2.113

E Mulyasa. (2011). Menjagi Guru Profesional Menciptakan Pembelajaran Kreatif dan Menyenangkan (11th ed.). Rosdakarya.

Fauzi, A. (2017). Kepemimpinan Kepala Madrasah Dalam Mengembangkan Lembaga Pendidikan Islam. Nidhomul Haq: Jurnal Manajemen Pendidikan Islam, 2(2), 42-53. http://ejournal.ikhac.ac.id/index.php/nidhomulhaq/article/view/31

Fitriani, C., Ar, M., \& Usman, N. (2017). Kompetensi Profesional Guru Dalam Pengelolaan Pembelajaran Di Mts Muhammadiyah Banda Aceh. Jurnal Administrasi Pendidikan: Program Pascasarjana Unsyiah, 5(2), Article 2. http://erepository.unsyiah.ac.id/JAP/article/view/8246

Hamalik, O. (2003). Perencanaan pengajaran berdasarkan pendekatan sistem. Bumi Aksara.

Hamzah B, U. (2007). Profesi kependidikan: Problema, solusi, dan reformasi pendidikan di Indonesia (Cet. 1). Bumi Aksara.

Hasanah, N. (2015). Dampak Kompetensi Profesional Guru Dalam Meningkatkan Mutu Pendidikan Madrasah Ibtidaiyah Di Kota Salatiga. INFERENSI: Jurnal Penelitian Sosial Keagamaan, 9(2), 445-466. https://doi.org/10.18326/infsl3.v9i2.445-466

Ikhwan, A. (2016). Manajemen Perencanaan Pendidikan Islam (kajian Tematik Al-Qurâ€ ${ }^{\mathrm{TM}}$ an Dan Hadist). Edukasi: Jurnal Pendidikan Islam, 4(1), 128-155. http://ejournal.staimtulungagung.ac.id/index.php/EDUKASI/article/view/194

Ilmi, M. U., Setiawan, F., Hikmah, M. N., Kharisma, A., Feryawan, D., \& Hanafie, A. A. (2021). The Basic Concepts of Evaluation and Its Implementation in IRE Lessons in The Pandemic Era. Tafkir: Interdisciplinary Journal of Islamic Education, 2(2), 175-190. https://doi.org/10.31538/tijie.v2i2.50

Indahwati, Y. D. (2018). Strategi Kepala Sekolah dalam pengembangan kompetensi profesional guru untuk meningkatkan mutu pendidikan di MA Hidayatul Mubtadiin Tasikmadu Lowokwaru Malang [Masters, Universitas Islam Negeri Maulana Malik Ibrahim]. http://etheses.uinmalang.ac.id/10267/

Indana, N. (2018). Penerapan Kurikulum Terintegrasi Dalam Mengembangkan Mutu Belajar Siswa (Studi Kasus Di Sma Darul 'Ulum 1 Unggulan Bppt Jombang). Nidhomul Haq: Jurnal Manajemen Pendidikan Islam, 3(2), 121-147. https://doi.org/10.31538/ndh.v3i2.80

Kartiko, A., Ma`arif, M., Zuana, M. M., Aprilianto, A., \& Rusydi, I. (2020, February 10). The Influence of Leadership, Compensation on Nurses' Performance in the Mother and Child Hospital 'Fatimah' Lamongan. Proceedings of the 2nd International Conference on Economics, Business, and Government Challenges, EBGC 2019, 3 October, UPN ' Veteran' East Java, Surabaya, Indonesia, Indonesia. http://dx.doi.org/10.4108/eai.3-10-2019.2291913

Khusnan, A. (2020). Implementasi Pendidikan Karaktermelalui Koperasi Jujur Di Madrasah Ibtidaiyah Sunan Ampel Sidoraharjo Kedamean Gresik. ZAHRA: Research and Tought Elementary School of Islam Journal, 1(2), 26-33. https://doi.org/10.37812/zahra.v1i2.123

Liu, I.-F. (2020). The impact of extrinsic motivation, intrinsic motivation, and social self-efficacy on English competition participation intentions of pre-college learners: Differences between high school and vocational students in Taiwan. Learning and Motivation, 72, 101675. https://doi.org/10.1016/j.lmot.2020.101675

Maarif, M. A., \& Rofiq, M. H. (2018). Pola Pengembangan Kurikulum Pendidikan Pesantren Berkarakter: Studi Implementasi Pendidikan Berkarakter di Pondok Pesantren Nurul Ummah Mojokerto. 13, 16. 
ZAHRA: Research And Tought Elmentary School Of Islam Journal Vol. (2) (2), (Agustus)(2021), (Halaman)(153-166)| 165

Mahfud, C. (2019). Evaluation of Islamic Education Curriculum Policy in Indonesia. Premiere Educandum: Jurnal Pendidikan Dasar Dan Pembelajaran, 9(1), 34-43.

Mathis, R. L., \& Jackson, J. H. (2011). Human resource management: Essential perspectives. Cengage Learning.

Miles, M. B., Huberman, A. M., \& Saldaña, J. (2014). Qualitative data analysis: A methods sourcebook (Third edition). SAGE Publications, Inc.

MOCH ARIF BURHANUDIN, 0102514008. (2018). Implementasi Total Quality Management Untuk Meningkatkan Mutu Sekolah (Studi Kasus di MA Raudlatul Ulum Guyangan Pati) [Masters, Universitas Negeri Semarang]. http://lib.unnes.ac.id/

Mufidah, N. Z. (2021). Integrated Curriculum Management In Forming Students Life Skills In SDI Qur'ani Al- Bahjah Tulungagung. ZAHRA: Research and Tought Elementary School of Islam Journal, 2(2), 83-98. https://doi.org/10.37812/zahra.v2i2.209

Mulyasa, E. (2006). Menjadi kepala sekolah profesional: Dalam konteks menyukseskan MBS dan $K B K$. Remaja Rosdakarya.

Mulyasa, E. (2013). Pengembangan dan implementasi kurikulum 2013 (Cetakan pertama). PT Remaja Rosdakarya.

Muslimin, T. A., \& Kartiko, A. (2020). Pengaruh Sarana dan Prasarana Terhadap Mutu Pendidikan di Madrasah Bertaraf Internasional Nurul Ummah Pacet Mojokerto. Munaddhomah: Jurnal Manajemen Pendidikan Islam, https://pasca.jurnalikhac.ac.id/index.php/munaddhomah/article/view/30

Pratama, Y. A. (2019). Implementasi Manajemen Pembelajaran Karakter Berbasis Total Quality Management Di SMP Muhammadiyah 3 Yogyakarta. Nidhomul Haq: Jurnal Manajemen Pendidikan Islam, 4(1), 1-22. https://doi.org/10.31538/ndh.v4i1.184

Qohar, M. A. (2016). StartegiMManajemen Hubungan Masyarakatt dalamm meningkatkann Mutuu Sekolah. 203.

Rahman, K. A. (2015). Rekrutmen Tenaga Pendidik dalam Peningkatan Mutu Madrasah Aliyah Negeri Insan Cendekia Jambi. Nadwa, 9(1), 23-38.

Rony, \& Jariyah, S. A. (2020). Urgensi Pendidikan Karakter dalam Membentuk Akhlak Peserta Didik. Tafkir: Interdisciplinary Journal of Islamic Education, 1(1), 79-100. https://doi.org/10.31538/tijie.v1i1.18

Rosidi, I. (2018). Pengembangan SDM Dalam Pembentukan Karakter Santri di Lembaga Pengabdian pada Masyarakat (LPM) Pondok Pesantren Wahid Hasyim Yogyakarta. TA'LIM: Jurnal Studi Pendidikan Islam, l(1), 106-120. jurnal.unisda.ac.id/index.php/talim/article/view/637

Rosyada, P. D. D. (2017). Madrasah Dan Profesionalisme Guru Dalam Arus Dinamika Pendidikan Islam Di Era Otonomi Daerah. Kencana.

Santosa, S., \& Devi, A. D. (2021). The Problematics Online Lectures on Human Resource Management Courses (HRM) at The Islamic College Level. Nazhruna: Jurnal Pendidikan Islam, 4(2), 261-271. https://doi.org/10.31538/nzh.v4i2.1452

Shodiq, M., Suyata, S., \& Wibawa, S. (2017). Developing quality evaluation instrument for Islamic Senior High School. Jurnal Penelitian Dan Evaluasi Pendidikan, 21(2), 189. https://doi.org/10.21831/pep.v21i2.15675

Siagian, S. P. (2003). Administrasi pembangunan: Konsep, dimensi, dan strateginya. Bumi Aksara.

Subandi, S. (2020). Quality Development Model of Management Islamic Religious Higher Education of Nahdltul Ulama. Jurnal Iqra': Kajian Ilmu Pendidikan, 5(2), 107-121. https://doi.org/10.25217/ji.v5i2.1195 
ZAHRA: Research And Tought Elmentary School Of Islam Journal Vol. (2) (2), (Agustus)(2021), (Halaman)(153-166)| 166 Sulistyorini, M. F. \&. (2012). Implementasi manajemen peningkatan mutu pendidikan islam / Muhammad Fathurrohman. Teras.

Surya, P., \& Rofiq, M. H. (2021). Internalisasi Nilai Karakter Jujur Dalam Proses Pembelajaran Di Kelas VIII Madrasah Tsanawiyah Unggulan Hikmatul Amanah Pacet Mojokerto. Munaddhomah: Jurnal Manajemen Pendidikan Islam, 2(1), 31-37. https://pasca.jurnalikhac.ac.id/index.php/munaddhomah/article/view/65

Winarti, E. (2018). Perencanaan Manajemen Sumber Daya Manusia Lembaga Pendidikan. Tarbiyatuna: Jurnal Pendidikan Ilmiah, 3(1), 1-26. http://ejournal.kopertais4.or.id/mataraman/index.php/tarbiyatuna/article/view/3434 